\title{
MEDICO-LEGAL ASPECT OF DENTAL PRACTICE
}

\author{
UPENDRA SINGH BHADAURIA, PRALHAD L DASAR, SANDESH N., \\ PRASHANT MISHRA, SHAIJAL GODHA
}

Department of Public Health Dentistry, Sri Aurobindo College of Dentistry, India

\begin{abstract}
Law influences every aspect of human activity, and dentistry in this regard is no exception. Ethical standards of the dental profession are seeing a steady decline, altruistic concepts being overridden by a market driven system. A deficient knowledge regarding the medico-legal aspects halts the effective implementation and delivery of efficient services. The review thus provides an overview of ethical standards, consents and their types, negligence,, determination of negligence, liabilities of dental practitioners and solicitors in dental practices, which comprehensively form an integral part of the medico-legal aspect of dental practice.
\end{abstract}

Keywords: legal medicine, dentistry, consent

\section{Introduction}

The concept of law is unique and no single definition can cover all its components. In simple terms Law may be defined as "an aggregate of rules enforceable by judicial means in a given country" [1]. Law influences every aspect of human activity, dentistry in this regard being no exception. The interface between Law and Dentistry is mediated by important statutes relating to health, the chief among which involves drug and cosmetics act, dentists act etc.The ethical standards of the dental profession are undergoing a steady decline, market driven system pushing away the altruistic concepts of the early teachers of the art. Today's corporate dentistry has degene $\neg$ rated to a common business practice whose concerns are strictly governed by profit and loss concerns, despitethe emergence of forensic odontology that ensures that every dentist must keep some kind of record for every patient they treat. An evaluation of knowledge regarding the maintenance of dental records among dentistsfound a very low percentage of dentists maintaining dental records [2]. The implementation and enhancement of the conceptual foundation of health laws is in its infancy. This review is based on the premise that there is a lack of knowledge regarding medico-legal aspect of dental professionals and patients, which in turn hinders effective implementation and delivery of dental services. We also provide an overview of the ethical aspects, ethical dilemmas relevance of consent, negligence, liability, medical decisions and implications from dentists and patients perspective.

Manuscript received: 12.01.2017

Received in revised form: 24.04.2017

Accepted: 09.05.2017

Address for correspondence: upendrazzz@gmail.com

\section{Ethics in dentistry}

Ethics is defined as the science of the human character and behavior in situations where distinctions must be made between the right and the wrong, duty must be followed, and good interpersonal relations maintained [3]. Medical ethics is a system of moral principles that apply values and judgments to the practice of medicine, whereas medical ethical dilemma is a type of behavior or phenomena by the healthcare providers that have the potential to become a problem. There are three conditions that must be present for a situation to be considered an ethical dilemma. The first condition occurs in situations when an individual, called the "agent," must make a decision about which course of action is best. The second condition for ethical dilemma is that there must be different courses of action to choose from. Third, in an ethical dilemma, no matter what course of action is taken, some ethical principle is compromised. In other words, there is no perfect solution. There are twotypes of Dilemmas: an "absolute" or "pure" ethical dilemma only occurs when two (or more) ethical standards apply to a situation but are in conflict with each other. An "approximate" dilemma occurs when there is conflicts between values, laws, and policies. Steps in approaching an ethical dilemma include recognizing the situation as one that raises an ethical problem, breaking the dilemma into its component parts, seeking additional information, including the patient's viewpoint, identifying any relevant law or professional guidance, subjecting the dilemma to critical analysis, justifying the decision with sound arguments [4].

With regard to the legal medicine in penitentiary, the primary task of the prison doctor and the other health 
care workers is the health and wellbeing of the inmates. The 7 essential principles for the practice of prison health care include free access to a doctor for every prisoner, equivalence of care, patient consent and confidentiality, preventive health care, humanitarian assistance, professional independence and professional competence [5].

Dental Ethics means moral duties and obligations of the dentist towards his patients, professional colleague and to the society [6]. The practice of dentistry is based on five ethical principles which include: To do no harm, To do Good, Respect for persons, Veracity, Beneficence, Justice, and is built upon important landmarks such as the Declaration Of Helsinki 1964, Belmont Report 1979, ICHGood Clinical Practice (GCP) 1997 and Declaration of Geneva.

\section{Consent}

The term consent means voluntary agreement, compliance, or permission [7]. Currently, the medical and dental professions are facing an ever increasing rate of malpractice suits. Patients facing such situations may seek legal aid for addressing their grievances. Therefore, one of the most important legal safeguards and moral obligations of dentists to their patients are obtaining consent for any course of health care action.

\section{Types of Consent}

\section{Implied consent}

Rowe described implied consent as: 'by being in the chair at the dental surgery with mouth open a patient implies that they are there for dental treatment' and continued 'in the past a dentist would undertake treatment as he or she saw fit, which the patient would accept without argument' [8].

\section{Proxy consent (Substitute Consent)}

This type of consent is utilized in the event the patient is unable to give consent because he/she is a minor or mentally unsound/unconscious. In such situations a parent or close relative can provide proxy consent [9-13].

\section{Loco parentis}

In an emergency situation in case of children, when parents/ guardians are not available, consent can be obtained from the person bringing the child for dental examination or treatment (For example: school teacher, warden, etc.) [14].

\section{Blanket consent}

It is a consent taken on a printed form that covers (like a blanket) almost everything a dentist or a hospital might do to a patient, without mentioning anything specifically. Blanket consent is legally inadequate for any procedure that has risks or alternatives [15-16].

\section{Oral consent}

Oral consent in front of witnesses and implied consent, which is determined by the behavior of the patient, is acceptable consent in certain situations. This is particularly true of simple procedures in dentistry [1].

\section{Negligence}

Alderson defined negligence as "the omission to do something which a reasonable man, guided upon those considerations which ordinarily regulate the conduct of human affairs, would do, or doing something which a prudent and reasonable man would not do" [1].

For an act to be considered negligent, the following aspects must be present [17]:

1. Doctor owed a certain standard of care.

2. Doctor did not maintain that standard.

3. An injury resulting from the lack of care.

4. A connection (proximity) between the negligent act and the resultant injury.

\section{When is it not Negligence?}

Normally, carelessness is not culpable or a ground for legal liability, as there is no wrongful intention but in medical negligence carelessness is taken seriously and the law has imposed a duty of carefulness on the doctor or health worker. But many other acts that patients commonly complain about don't fulfill the requirements mentioned earlier. A review of consumer cases, show that some of the situations mentioned below, do not come under medical negligence, e.g.

- Inability to obtain consent form in an emergency.

- Patient's dissatisfaction with progress of treatment.

- Inability to get desired relief.

- Precedence of one patient over the other based on priority.

- Charging an amount that the patient thinks is exorbitant

\section{Elements of Negligence}

Legally the tort (civil wrong) of negligence can be established against a dental practitioner only if the following elements are present [1]:

1. Dentist has a duty to care for the patient.

2. A violation of the above duty.

3. An injury to the patient.

4. A proximate relationship between the violation and the injury.

\section{Test of Negligence [18]}

\section{The Bolam Test}

The locus classicusof the test for the standard of care in law, required of a doctor, developed from this landmark case. Mr Justice McNair, in his direction to the jury, said: [a doctor] is not guilty of negligence if he has acted in accordance with the practice accepted as proper by a responsible body of medical men skilled in that particular art. Putting it the other way round, a man is not negligent, if he is acting in accordance with such a practice, merely because there is a body of opinion who would take a contrary view.

In practical terms, the effect of the Bolam test is that a finding of negligence is not made where the defendant doctor has acted in accordance with a responsible body of medical opinion. This test has been repeatedly approved 
at appellate level and is enshrined in law. The principal criticism of the Bolam test is that it fails to draw a distinction between 'what is done' and 'what ought to be done'.

\section{The Bolitho Test}

The actions being accepted in the Bolam test must be capable of logical analysis. Even if a responsible body of fellow professionals would see the actions as proper, the court can still rule their amount to negligence. In practical terms, the first stage would be for the court to assess whether the decision had responsible peer support, based on an approach that was structured, reasoned and defensible. The professed opinion must withstand 'logical analysis.' This broadly reflects the Bolam test as it is known. The second stage, and this is where Bolitho might really take effect, is to assess on a 'risk analysis' basis the validity of accepting the treatment or course of action offered by the defendant and, more importantly, the validity of rejecting competing decisions. In undertaking such an analysis, the court may look at a number of factors, including the magnitude of the risk, the comparative risks of alternative interventions and treatments, the seriousness of the consequences, the ease by which the risk might be avoided, and the implications of such avoidance in terms of finances and resources of healthcare.

\section{Liability of doctors}

How are Doctors Liable for Negligence? [19]

Doctors are liable under four heads.

1. Tortuous liability

2. Contractual liability

3. Criminal liability

4. Statutory liability

Tortuous Liability (Civil Liability)

Tortuous liability may be of two types:

1. Primary liability

2. Vicarious liability

\section{Primary Tortuous Liability}

When a doctor or dentist is directly liable for an act of negligence in his clinic or hospital it is called primary 'liability'. Most dental negligence would come under this category.

\section{Vicarious Liability}

Dentists employed by a hospital: institutions are often not primarily responsible for negligence. They may be said to have vicarious liability through the hospital. The hospital has the liability for the negligence of an employee.

\section{Contractual Liability}

Continue to treat and not terminate until patient is curedor the patient discontinues treatment. In most instances if there is no written contract their liability will essentially lie within the realm of tortuous liability.

\section{Criminal Liability}

Recent trends indicate that hospitals also may be held vicariously liable just as in civil liabilities. Criminal liability is penal and involves punishment in the form of imprisonment or fine, or both. Criminal negligence is considered to be a crime against society and not just the aggrieved party.

\section{Statutory Liability}

A doctor or nursing home is liableif there is any infringement of statutes. They then become accountable to s statutory body. The liability depends on the kind of refinement and the provisions in the statute to deal with.

\section{Legal Medicine in Romania [20]}

Before the year 2000, starting with 1966, Romania was centralized: The Institute of Legal Medicine was of course, in Bucharest, while in the other important cities of Romania several branches of theInstitution were functioning financially and administratively subordinated to the center. Today, the national grid system of legal medicine has in Romania three levels i.e. six independent Institutes of Legal Medicine, which coordinate the professional activity in several counties,Services of Legal Medicine, which solve the cases at county level, Consulting Rooms of Legal Medicine in the most important cities. With regard to the private practice according to the new law of 2000, the experts have the right to private practice of expert advice. In other words, we are not able to give to the patient medicolegal official papers but only to explain or give advice to the question marks of one of the parts, or to interpret the results of an autopsy or a traumatic examination.

\section{Medical Decisions [21]}

A doctor cannot make these decisions for the patient; someone else must decide on the patient's behalf. Except in an emergency, no medical treatment may be given to any patient without the informed consent of the patient or the proxy. When you make medical decisions for someone else, you are acting as a health care proxy — which is the general term used in this handbook for a person who makes decisions for someone else. There are three kinds of proxies:

1. Health care agent. Your relative or friend has signed a legal document called an advance directive, naming you to make health care decisions for him or her in case something happens. Some people call this a durable power of attorney for health care or agent. If you are named in an advance directive to make medical decisions for someone else, you are a health care agent.

2. Guardian. A court may appoint you as a medical guardian and specifically authorize you to make health care decisions for someone else. A guardian is directly answerable to the appointing court.

3. Surrogate. Even when nobody has formally named you as a health care agent, you may still be asked informally to make medical decisions for someone else. Family members or close friends are sometimes called upon to make decisions when the patient cannot, as they usually know the patient best and are most familiar with the patient's wishes and values. This type of proxy is known as a surrogate.

If you are a health care proxy, your job is to make 
decisions and take actions that a patient would make or do, if able. This includes getting the same medical information the patient would get. Talking with the medical team, asking for consultations and second opinions, Consenting to or refusing medical tests or treatment, deciding whether to transfer,getting the doctor and other medical professionals to communicate with the patient. Being a proxy can be difficult. But there are several key things to remember.You can say yes or no. Anxiety is normal. Keep the patient involved, It's not about your money, Inaction has consequences, too, respect culture

\section{Solicitors in Dental Practice [22]}

In order to ensure negligence solutions for patients and doctors a number of dental law solicitors have emerged in recent years and are providing free consultancy services towards dental negligence claims, the chief among them include Dental Law Partnerships, Slater Gordon Dental Negligence Solicitors etc.

\section{Conclusion}

As the awareness in developing societies is increasing, people are changing attitudes toward medical and dental procedures; this increases the probability of suing dental practitioners for their misconduct. Law is universal and is applicable to all, however morality or ethics may differ from person to person, hence a minimum threshold of ethics imposed by law should be a pre requisite.Law should not be a source of fear or an obstruction in the delivery of professional services. Law when applied properly always brings peace and sense of equality prevails. Compensation and punishments to civil wrong and criminal act, respectively, try to restore peace but ethics if performed in uniformity and correct intent can help society in a better way. The profession should take an inward look and correct malpractices and distortions, which have given a negative image to a noble profession. An incorporation of medical teachings can not only help uplift medical and dental practice, but also maintain professional secrecy. We must also understand the aim of medicine is "do not harm", hence while healing in helping we must not harm the patient.

\section{Implication}

The implication of understanding medico legal aspect in dentistry does not rest only with its use in dental practice. The understanding also plays a vital role in dental public health programmes. Understanding of medico legal aspect provides protection against commercial, legal and medico legal litigation. It provides a practical implication of understanding the theoretical aspect of medical and dental history, chart notes, radiographs, photographs and models, because, legally, dentist written records carry more weight than the patient's recollections.

\section{References}

1. Paul G. Medical law for dental surgeon. JaypeeDigital, 2004: ch. 5, p. 29.

2. Gupta A, Mishra G, Bhutani H, Hoshing C, BhallaA. Forensic revolution need maintenance of dental records of patients by the dentists: A descriptive study. J IntSocPrev Community Dent. 2016;6(4):316-320.

3. Dunning JM. Principles of Dental Public Health. 4th ed. Harvard University Press; 1986: 10-11.

4. Hommadi J. Medical Ethical Dilemmas [Online presentation]. Available from http://afhsr.med.sa/cqi_web/web/cqi_docs/4. Education\%20\&\%20Training/3.Conferences/ethics $\% 20$ sumposym/dr.+jamalMedical+Ethical+dilemmas.pdf

5. Vienna JP. Medical ethics in prison [Online presentation]. Available from www.unodc.org/documents/balticstates/ EventsPresentations/FinalConf_24-25Mar11/Pont_25_March.pdf 6. Vivekanand SK. Manual of Community Dentistry. India: Jaypee Publishers; 2004

7. Kohli A. Medical consent in India - Ethical and legal issues. Anil Aggrawal's Internet Journal of Forensic Medicine and Toxicology. 2007;8: 19.

8. Rowe AH. Consent. Dent Update. 1994;21:188-190.

9. World Medical Association Declaration of Helsinki. Ethical Principles for Medical Research Involving Human Subjects.2008:1-5.

10. Council for International Organizations of Medical Sciences. International ethical guidelines for biomedical research involving human subjects. Bull Med Ethics. 2002;(182):17-23.

11. National Bioethics Advisory Commission. Ethical and policy issues in international research. Washington, DC.2000. Available from: https://bioethicsarchive.georgetown.edu/nbac/pubs.html 12. Nuffield Council on Bioethics. The ethics of research related to health care in developing countries. London: Nuffield Council on Bioethics.2002.

13. Kukreja P, Godhi S, Basavraj P. Consumer Protection Act and Medical Negligence- A Brief Insight. Journal of the Indian Association of Public Health Dentistry.2011; 17: 522-527.

14. Krishnan NR, Kasthuri AS. Informed Consent. Med J Armed Forces India. 2007;63:164-166.

15. Lunshof JE, Chadwick R, Vorhaus DB, Church GM. From genetic privacy to open consent. Nat Rev Genet. 2008;9:406-411. 16. Manthous CA, DeGirolamo A, Haddad C, AmoatengAdjepong Y. Informed consent for medical procedures: local and national practices. Chest. 2003;124:1978-1984.

17. D' Cruz L. Legal aspects of general dental practice. Churchill Livingstone;2006:203-205.

18. Samanta A, Samanta J. Legal standard of care: a shift fromthe traditional Bolamtest.Clin Med (Lond). 2003;3(5):443-446.

19. KirtiGoel, ParulGoel, SumitGoel. Negligence and its legal implications for dental professionals: a review. TMU J. 2014; Dent 1(3):113-118

20. Scripcaru A, Bulgaru Iliescu D, Scripcaru C. The past, present and future of legal medicine in Romania. International Journal of Medical Dentistry.2016;5(19):3-83.

21. Making Medical Decisions for Someone Else. Available from: http://www.vtethicsnetwork.org/forms/making_medical_ decisions.pdf.

22. http://www.slatergordon.co.uk/clinical-and-medical-negligence/ dental-errors/. 